\title{
Os Estados Unidos e as Relações Internacionais contemporâneas*
}

Luis Fernando Ayerbe**

(1) fim do mundo bipolar, que concentrou as principais atenções nos debates sobre a estrutura das relações internacionais da segunda metade do século XX, traz como um de seus desdobramentos intelectuais e políticos mais importantes o ressurgimento do imperialismo como foco de reflexão sobre a ordem mundial em formação.

Para diversos analistas, tanto conservadores como críticos em relação ao capitalismo, a atual supremacia desse sistema e a emergência dos Estados Unidos como única superpotência global, apesar de inquestionáveis, trazem como elemento de indagação seu significado histórico, seja como fase inaugural de um período de paz e prosperidade, seja como estágio final de um modelo civilizatório que teve no Ocidente seu grande impulsor.

\footnotetext{
* Artigo recebido em agosto e aceito para publicação em setembro de 2005.

** Professor do Departamento de Economia da Universidade Estadual Paulista (Unesp) e do programa de Pós-Graduação em Relações Internacionais da Unesp/Unicamp/PUC-SP.
}

CONTEXTO INTERNACIONAL Rio de Janeiro, vol. 27, no 2, julho/dezembro 2005, pp. 331-368. 
Evidentemente, não é a primeira vez na história do capitalismo que essas questões se fazem presentes. O mesmo dilema acompanhou os debates sobre a longevidade do sistema e as possibilidades estruturais da hegemonia ocidental na transição do século XIX para o XX. Diante do impasse na II Internacional, decorrente de profundas controvérsias sobre os impactos das mudanças sistêmicas na estratégia da revolução socialista, as teses de Lênin sobre imperialismo fundamentam o programa político que orientou a vitória bolchevique na Rússia. Para Lênin, o imperialismo representa a negação, via expansão externa, das contradições internas do modo de produção capitalista nos países centrais. A partilha do mundo entre as grandes potências e a expansão do capitalismo financeiro gera uma nova divisão internacional do trabalho, deslocando os sintomas agudos da gravidade da crise do centro para a periferia do sistema. É aqui que se localizam os elos fracos da cadeia imperialista, junto com as condições objetivas da revolução.

Analistas da evolução mais recente do capitalismo, como Michael Hardt e Antonio Negri (2001), dão por encerrada a fase imperialista caracterizada por Lênin. Para eles, a expansão territorial impulsionada pelos Estados-nação deu lugar ao Império, abarcador da totalidade. Já não há lado de fora, instalou-se o reino do mercado mundial, tornando obsoletas as separações de países com base nas noções tradicionais de hierarquia dos mundos. Na nova ordem mundial, perdeu sentido a diferenciação entre espaços internos e externos.

Do ponto de vista das abordagens legitimadoras da nova realidade, $\mathrm{o}$ Império representa o fim da história; nesse sentido, os autores reconhecem as bases concretas que alimentam perspectivas como a de Fukuyama, para quem desapareceram definitivamente as alternativas ao capitalismo, eliminando as bases de conflito originárias de forças externas ao sistema. Para Hardt e Negri (idem), que se situam entre os críticos da ordem, o Império representa um avanço em rela- 


\section{Os Estados Unidos e as Relações Internacionais Contemporâneas}

ção ao imperialismo, da mesma forma que o capitalismo expressa um processo evolutivo sobre os modos de produção que o antecederam.

Diferentemente dos autores de Império, que questionam a relevância das perspectivas orientadas pela lógica do Estado-nação, Arrighi e Silver (2001) centralizam sua análise do capitalismo atual no papel exercido pela sua potência hegemônica, que consideram em estado de crise sistêmica. Analisando os períodos de transição hegemônica holandês-britânico e britânico-norte-americano, apontam para a existência de padrões comparáveis de crise e reorganização marcados por "três processos distintos mas estreitamente relacionados: a intensificação da concorrência interestatal e interempresarial; escalada dos conflitos sociais; e o surgimento intersticial de novas configurações de poder" (idem:39).

Independentemente das especificidades de cada situação histórica, as três crises hegemônicas apresentam como elemento comum as expansões financeiras, que permitem ao líder dominante um acesso privilegiado aos recursos financeiros mundiais, contribuindo para adiar temporariamente o fim da sua liderança.

O atual contexto de expansão financeira, que tem como centro os Estados Unidos, representa para os autores um sinal de crise hegemônica que, no entanto, apresenta algumas peculiaridades em relação às fases anteriores:

1) A potência em declínio não tem concorrentes no campo militar, mas tornou-se dependente, na administração do seu poder, de recursos financeiros de outros centros de acumulação de capital, marcadamente Europa ocidental e Japão.

2) Diferentemente do processo de globalização das últimas décadas do século XIX, em que os Estados-nação eram protagonistas funda- 


\section{Luis Fernando Ayerbe}

mentais da internacionalização do capital, há uma diminuição do seu poder em detrimento do setor privado transnacional.

3) Em comparação ao aumento dos conflitos sociais que acompanhou os períodos de transição holandesa e britânica, especialmente os vinculados à luta antiescravista e ao movimento operário, os autores identificam uma perda conjuntural de poder dos movimentos sociais. No entanto, os efeitos estruturais desagregadores da atual configuração global criam novas fontes de conflito para as quais não existe capacidade adequada de resposta.

4) Nas transições hegemônicas anteriores, a emergência de uma nova potência precipitou o desmoronamento do antigo poder: Inglaterra em relação à Holanda, Estados Unidos em relação à Inglaterra. Embora os autores coloquem em evidência a crescente expansão econômica do Leste da Ásia, isto não configura uma ameaça ao poderio militar estadunidense. Esta situação impõe uma marca peculiar à atual mudança no sistema mundial, cujo desfecho poderá ser mais ou menos problemático dependendo da atitude dos Estados Unidos:

“[...] essa nação tem uma capacidade ainda maior do que teve a GrãBretanha, cem anos atrás, para converter sua hegemonia decrescente em uma dominação exploradora. Se o sistema vier a entrar em colapso, será sobretudo pela resistência norte-americana à adaptação e à conciliação. E, inversamente, a adaptação e a conciliação norte-americanas ao crescente poder econômico da região do Leste da Ásia é condição essencial para uma transição não catastrófica para uma nova ordem mundial" (idem:298).

As respostas do governo dos Estados Unidos aos atentados de 11 de setembro de 2001 representaram um teste importante para os argumentos da crise de hegemonia. Sem rejeitar completamente as teses de Arrighi e Silver (idem), Ana Esther Ceceña (2002:181) sustenta que "a hegemonia estadunidense está em decadência ao mesmo tempo em que se encontra mais forte e consolidada do que nunca antes na história". 


\section{Os Estados Unidos e as Relações \\ Internacionais Contemporâneas}

Em apoio a essa afirmação, aparentemente contraditória, Ceceña destaca os fatores que sustentam e comprometem a manutenção da posição hegemônica. Paralelamente à supremacia militar apontada por Arrighi e Silver (2001), adquirem relevância as dimensões econômica e cultural.

No plano econômico, verifica-se a

"Superioridade tecnológica em quase todos os campos estratégicos da concorrência [...]; superioridade no controle de fontes naturais de recursos estratégicos; rede produtiva de maior amplitude e densidade do mundo; manejo do mercado de trabalho mais diverso do ponto de vista cultural, geográfico e de níveis e tipos de conhecimento; capacidade de controle dos mecanismos de organização econômica mundial tais como políticas gerais (BM, OMC e outros), dívida (FMI, FED e outros), protocolos de regulamentação etc." (Ceceña, 2002:168-169).

No âmbito cultural, reconhece a

"Capacidade para generalizar, ainda que com contradições, um paradigma cultural correspondente ao american way of life - e ao que este significa traduzido a outras situações e culturas - que coincide com a homogeneização de mercados, a estandardização da produção e a uniformização das visões sobre o mundo" (idem:169).

No interior do governo dos Estados Unidos, consolidam-se as posições favoráveis ao aprofundamento da hegemonia, conduzindo a um intervencionismo que incorpora no seu discurso as três dimensões apontadas por Ceceña (idem): as invasões do Afeganistão e do Iraque, anunciadas como resposta militar às novas ameaças terroristas, em países situados em uma área geográfica estratégica em termos de acesso a reservas petrolíferas, governados por regimes políticos emblemáticos da oposição ao "modo de vida ocidental".

Em relação aos fatores limitantes da hegemonia, a autora coincide com Arrighi e Silver (2001) na caracterização dos impasses sociais gerados pelo sistema, não deixando aos setores populares outra alternativa fora da sua negação. "Um sistema sem opções, sem saídas, 
sem soluções para as imensas maiorias negadas que não têm maneira de se sustentar e criam, como dizia Marx, as condições da sua autodestruição" (Ceceña, 2002:182).

\section{Choque de Civilizações: Uma Ideología Nacional}

O reconhecimento de que a hegemonia dos Estados Unidos se tornou uma realidade incontestada da Nova Ordem Mundial abre espaço para um processo de debates no interior do establishment vinculado à política externa do país sobre a caracterização da nova etapa e a formulação de uma estratégia internacional adequada. A substituição do paradigma da Guerra Fria requer uma redefinição dos interesses nacionais, desafios e ameaças a enfrentar.

A partir de uma perspectiva conservadora, Samuel Huntington chama a atenção para as consequiências negativas do unilateralismo da política externa norte-americana do pós-Guerra Fria. Diferentemente de Arrighi e Silver (2001), que situam na história do capitalismo as referências do que consideram uma crise da atual potência hegemônica, Huntington preocupa-se com os fatores que podem corroer a continuidade da civilização ocidental e, conseqüentemente, dos Estados Unidos como nação.

Em artigo publicado em 1993 na revista Foreign Affairs, Huntington (1993) propõe uma nova abordagem sobre a dinâmica das relações internacionais, desencadeando um amplo debate. Na sua caracterização da Nova Ordem Mundial, quatro aspectos são destacados: 1) a derrota do socialismo, promotor de um sistema econômico que questionava a propriedade privada dos meios de produção; 2) a disseminação global da lógica do mercado; 3) o controle das instituições econômicas multilaterais (FMI, Banco Mundial, OMC) pelos países do capitalismo avançado; 4) a conquista da superioridade militar por parte da Organização do Tratado do Atlântico Norte (OTAN). 


\section{Os Estados Unidos e as Relações \\ Internacionais Contemporâneas}

$\mathrm{O}$ autor considera que as principais fontes de conflito na ordem em configuração não serão políticas, ideológicas ou econômicas, elas virão das linhas que separam as diversas culturas e civilizações: ocidental, confuciana, japonesa, islâmica, hindu, eslava ortodoxa, latino-americana e africana.

Da perspectiva de Huntington (1997), a noção de que a derrota do inimigo soviético elimina o último obstáculo ao avanço triunfal da democracia liberal, do capitalismo de mercado e dos valores da civilização ocidental é questionável. Colocando-se na contramão das posturas ufanistas, explicita sua oposição às teses do fim da história, destacando os genocídios que emergem após a queda do muro de Berlim, de frequiência mais comum do que em qualquer período da Guerra Fria: "O paradigma de um só mundo harmônico está claramente divorciado demais da realidade para ser um guia útil no mundo pós-Guerra Fria" (idem:33).

Em uma ordem mundial em que as principais fontes de conflito são de origem cultural, a afirmação de identidades adquire especial relevância, implicando em desdobramentos específicos na definição do interesse nacional. Referindo-se aos Estados Unidos, Huntington destaca a necessidade de se estabelecer um consenso sobre as bases constitutivas da cultura do país, antes de definir quais são seus interesses. No entanto, como o próprio autor reconhece, "nós só sabemos quem somos quando sabemos quem não somos e, muitas vezes, quando sabemos contra quem estamos" (idem:20).

Com o fim da Guerra Fria, desaparece o "outro" que encarnava a negação do modo de vida americano e justificava a necessidade de uma postura nacional coesa e militante. As transformações demográficas, com novas ondas migratórias de população de origem predominantemente hispânica, influenciam mudanças raciais, religiosas e étnicas que podem colocar obstáculos à tradicional capacidade do país de as- 


\section{Luis Fernando Ayerbe}

similar outras culturas. Nessa perspectiva, a afirmação da identidade requer uma nova demarcação das fronteiras em relação aos outros.

Essa tarefa tem dimensões internacionais e domésticas. O mundo das civilizações é um campo de muitas incertezas, em que a ação dos atores responde a diversos tipos de racionalidades, muito mais complexas do que a lógica bipolar da Guerra Fria. Conhecer-se e conhecer os outros exige cautela. Na política externa, Huntington recomenda uma postura não intervencionista. Os Estados Unidos devem reconhecer os espaços civilizacionais e os seus respectivos Estados-núcleos, evitando o envolvimento nos conflitos internos das outras civilizações.

Analisando a inserção internacional do país após o fimm da Guerra Fria, Huntington (2000) identifica três etapas: $1^{\text {a }}$ ) um breve momento unipolar, tipificado na ação unilateral na Guerra do Golfo; $2^{a}$ ) um sistema unimultipolar em andamento, que prepara a transição para a terceira etapa; $3^{\text {a }}$ ) etapa multipolar. No contexto atual, o autor percebe uma contradição entre o sistema unimultipolar e a política externa adotada a partir do governo Clinton, que mantém características típicas da unipolaridade, com uma postura imperialista que provoca a insatisfação dos aliados tradicionais e estimula a solidariedade entre os adversários. Essa política se expressa em ações bastante evidentes como

“[...] pressionar outros países a adotar valores e práticas norte-americanas no que diz respeito aos direitos humanos e à democracia; evitar que outros países adquiram capacidade militar que possa constituir um desafio à superioridade de seu arsenal de armas convencionais; impor o cumprimento de suas próprias leis fora de seu território a outras sociedades; atribuir classificações aos países de acordo com seu grau de aceitação aos padrões norte-americanos no que concerne a direitos humanos, drogas, terrorismo, proliferação de armas nucleares e de mísseis ou, mais recentemente, liberdade de religião; aplicar sanções aos países que não atendam tais padrões; promover os interesses empresariais norte-americanos sob a bandeira do livre comércio e da abertura de mercados; influenciar as políticas do Banco Mun- 


\section{Os Estados Unidos e as Relações \\ Internacionais Contemporâneas}

dial e do Fundo Monetário Internacional segundo esses mesmos interesses corporativos; intervir em conflitos locais de pouco interesse direto para o país; impor a outros países a adoção de políticas econômicas e sociais que beneficiarão os interesses econômicos norte-americanos; promover a venda de armas para o exterior ao mesmo tempo procurando evitar vendas de natureza semelhante por parte de outros países" (idem:15).

Referindo-se ao contexto posterior ao 11 de Setembro e ao debate sobre as posições que deverão ser assumidas na defesa dos interesses nacionais do país, Huntington (2004) sistematiza três abordagens diferentes: 1) cosmopolita, que envolveria a renovação das concepções favoráveis à abertura ao mundo antes do ataque terrorista; 2) imperial, vinculada aos setores neoconservadores presentes no governo Bush, que defendem a estruturação do mundo à imagem e semelhança do american way of life; e 3) nacional, próxima da sua própria perspectiva, que busca preservar e enaltecer os valores, princípios e qualidades que estariam presentes nas origens da construção da nação. Dessa perspectiva, o "cosmopolitismo e o imperialismo procuram reduzir ou eliminar as diferenças sociais, políticas e culturais entre a América e as outras sociedades. Uma abordagem nacional reconheceria e aceitaria aquilo que distingue a América de outras sociedades" (idem:364).

A grande repercussão das teses de Huntington nos debates sobre a nova configuração das relações internacionais após o fim da bipolaridade não esteve isenta de controvérsias, com críticas que destacam desde a ausência de rigor conceitual na caracterização das civilizações existentes até a adoção de um culturalismo com nítidas conotações ideológicas, que enaltece as virtudes da "civilização ocidental" em detrimento do "resto" e influencia posturas isolacionistas na política externa, animadas por argumentos discriminatórios em relação às outras civilizações (Ayerbe, 2003).

Sem desconsiderar a validade desses questionamentos, se avaliada à luz da sua intencionalidade explícita de defesa dos interesses nacio- 
nais dos Estados Unidos, a análise de Huntington apresenta uma racionalidade estratégica de longo alcance que nos parece relevante.

Para o autor, a derrota da União Soviética colocou o Ocidente em uma situação de inquestionável supremacia global. Na ausência de uma superpotência inimiga do sistema, os apoios incondicionais e a noção de "guardião do mundo livre" perdem significado. Os assuntos mundiais ganham outra dimensão. Perdas e danos na concorrência por mercados, ou situações de desequilíbrio político geradoras de conflitos regionais, deixam de ser vistos com lentes ideológicas. Nesse contexto, assumir perspectivas missionárias pode levar a última superpotência a um processo de isolamento. A administração da hegemonia exige um cuidadoso trabalho de geração de novas alianças e tratamento negociado das divergências, buscando amenizar ou, no melhor dos casos, eliminar o caráter antagônico das contradições, o que torna contraproducentes as posturas arrogantes e intervencionistas. Na raiz do seu culturalismo, está a crescente preocupação com novas fontes de conflito que, embora não coloquem em questão o sistema, podem afetar a governabilidade. Para Huntington, após as vitórias da Guerra Fria, não há nada decisivo a ser conquistado.

Nesse sentido, há uma diferença substancial em relação à análise de Arrighi e Silver (2001), que situa na história do capitalismo as referências atuais do que consideram uma crise da hegemonia norte-americana. A principal preocupação de Huntington não é com as ameaças externas. Embora chame a atenção para o crescente poderio da China, não vê possibilidades de riscos que ponham em questão a existência do sistema. O principal dilema é a continuidade dos fundamentos culturais que colocaram a civilização ocidental, e os Estados Unidos, na liderança do mundo. Uma vez atingido o ápice dessa trajetória, como evitar os sinais de declínio presentes em alguns valores e comportamentos que tendem a minar a identidade nacional?

No âmbito internacional, a crescente ampliação do abismo entre a riqueza e a pobreza, uma das tendências da atual realidade mundial so- 


\section{Os Estados Unidos e as Relações Internacionais Contemporâneas}

bre a qual existe bastante consenso, sinaliza que a prosperidade anunciada pela vitória do capitalismo liberal é estruturalmente restrita. Deste ponto de vista, qual o sentido de estimular expectativas sobre a inevitável disseminação global do american way of life?

Diferentemente de Hardt e Negri (2001), Huntington não deixa dúvidas sobre o caráter imperialista da ação integrada envolvendo o Estado, o setor privado e os organismos multilaterais. A imposição de modelos econômicos que, em nome da liberdade de mercado, promovem basicamente a maximização dos lucros das empresas norte-americanas no exterior, pode ter conseqüências danosas nos países e regiões com menor capacidade de adaptação à competição global, acentuando as disparidades entre ricos e pobres e contribuindo para inflamar sentimentos fundamentalistas.

É com base nesses pressupostos que critica explicitamente a abordagem do "fïm da história", típica da tradição imperial do Ocidente, que prescreve ao resto do mundo modos universais de convívio humano. Se bem considera essa perspectiva válida em outros contextos, ajudando a promover sua expansão, deixou de ser aconselhável. No plano internacional, pelas conseqüências antes mencionadas, internamente, porque estimula um clima intelectual propício à acomodação no desfrute da vitória e à perda de vigilância em relação aos inimigos.

Para Chalmers Johnson (2004), um crítico da política externa de George W. Bush, a atuação internacional dos Estados Unidos aparenta adotar a tese do Choque de Civilizações, embora em um sentido oposto do isolacionismo prescrito por Huntington, recriando um "missionarismo" fundamentalista cristão. Apesar de avaliar negativamente os custos econômicos da dominação militar do mundo, que desvia recursos da economia privada e contradiz o espírito de livre iniciativa, Johnson (idem:310) não assume uma posição definitiva sobre o futuro: "deve-se reconhecer que qualquer estudo sobre o nos- 
so império é um trabalho em andamento. Mesmo que possamos conhecer seus resultados eventuais, não está totalmente claro o que vem depois".

\section{Unilateralismo/Multilatera- Iismo: A "Doutrina Bush"}

Na era das armas nucleares, não é possível imaginar a emergência de novas superpotências como resultado da derrocada militar das antigas. Como mostra a experiência da ex-União Soviética, a implosão pode resultar da incapacidade do sistema de responder às pressões originárias de um cenário internacional cuja dinâmica se torna incompatível com a manutenção da ordem vigente.

A Rússia apresenta-se como o elo fraco das crises que inauguraram e fecharam o curto século XX delimitado por Hobsbawm. A revolução vitoriosa de 1917 gerou um modelo de desenvolvimento que transformou o país em protagonista central das relações internacionais, cabendo-lhe papel de destaque na vitória dos aliados na Segunda Guerra e compartilhando com os Estados Unidos o status de superpotência nas décadas da Guerra Fria. No entanto, sucumbiu perante os desafios da radicalização de antagonismos promovida pelo governo Reagan. Os crescentes esforços econômicos exigidos pela manutenção do equilíbrio de poder minaram a capacidade de sustentação do sistema, em um contexto em que os rápidos avanços no campo tecnológico aprofundam as disparidades entre os países que lideram o processo de inovação, marcadamente as potências capitalistas, e aqueles como a antiga URSS, cujo crescimento permanece fortemente dependente da disponibilidade de mão-de-obra e de recursos naturais.

No caso dos Estados Unidos, é possível caracterizá-lo, na perspectiva de Arrighi e Silver (2001), como o atual elo fraco da cadeia impe- 


\section{Os Estados Unidos e as Relações \\ Internacionais Contemporâneas}

rialista? Como bem mostra Ceceña (2002), a hegemonia do país não se dá apenas no campo militar, mas também no econômico e cultural.

Do meu ponto de vista, o unilateralismo da política externa de George W. Bush não é uma resposta improvisada aos atentados de 11 de setembro, é uma marca característica da sua gestão. Desde a posse, redefine a posição do país frente a importantes tratados internacionais, sinalizando várias diferenças em relação à administração anterior, como as decisões contrárias à ratificação do protocolo de Kyoto, à criação do Tribunal Penal Internacional (TPI) e à proposta de revisão do Tratado Anti-mísseis Balísticos (TAB).

Os atentados contribuem para consolidar no interior do establishment as posições favoráveis à entronização dos Estados Unidos como principais responsáveis pela vigilância e punição dos inimigos da ordem, já não como guardiões do "mundo livre", mas como protetores das fronteiras que separam a "civilização" da "barbárie", dotando a guerra declarada ao terrorismo de contornos bem amplos. A caracterização dos grupos patrocinadores do terrorismo é suficientemente ambígua, como que para justificar a inclusão ou exclusão de organizações ou movimentos de acordo com os interesses conjunturais do país. Conforme explicitou Colin Powell (2001), secretário de Estado no primeiro mandato de Bush: "Qualquer organização que esteja interessada em operações terroristas para subverter os governos legítimos, democraticamente eleitos, ou governos que representam a vontade de seu povo, é uma ameaça".

A despeito do apoio internacional recebido pelos Estados Unidos no ataque ao Afeganistão, a rápida vitória militar contribuiu para fortalecer o unilateralismo. O resultado foi a formulação de uma nova concepção na orientação das relações internacionais do país, que passou a ser conhecida como "Doutrina Bush", cujo alvo imediato foi o regime iraquiano de Saddam Hussein. 


\section{Luis Fernando Ayerbe}

Conforme explicita o documento "A Estratégia de Segurança Nacional dos EUA" (NSC, 2002), dado a conhecer pela Casa Branca em setembro de 2002, a contenção e a dissuasão, que nortearam a política externa nas décadas da Guerra Fria, perdem centralidade para a preempção e a prevenção, justificando ataques contra Estados e organizações suspeitos de planejarem atos de hostilidade contra o país e os seus aliados.

"Na Guerra Fria, especialmente no contexto da crise dos mísseis cubanos, nós geralmente enfrentamos um status quo, um adversário com aversão ao risco. A contenção era uma defesa eficaz. Mas a contenção baseada somente na ameaça da retaliação tem menos probabilidade de funcionar contra líderes de Estados fora-da-lei com maior disposição para assumirem riscos, jogando com as vidas de seus povos e a riqueza de suas nações. Para prevenir ou impedir tais atos hostis por parte dos nossos adversários, os Estados Unidos, se necessário, atuarão preventivamente" (idem:15).

A nova postura está animada pela exaltação das virtudes do capitalismo e da democracia liberal, pilares de um modo de vida que se pretende universal: "Os grandes conflitos do século XX, travados entre a liberdade e o totalitarismo, terminaram com a vitória decisiva das forças da liberdade - e com um único modelo sustentável para o êxito de uma nação: liberdade, democracia e livre iniciativa" (idem:1).

A opção pelo unilateralismo, apresentado como custo inevitável do combate às novas formas de terrorismo, recebe críticas de funcionários da administração anterior, que se posicionam em favor de uma concepção multilateral das relações internacionais. De acordo com Joseph Nye Jr. (2004), secretário adjunto da Defesa no governo Clinton, o unilateralismo estaria solapando as bases do poder brando (soft power) do país, pautado pela atração exercida por seus valores, instituições e ideologia, levando a uma exacerbação pouco inteligente do poder duro (hard power), associado à capacidade de induzir a determinados comportamentos. 


\section{Os Estados Unidos e as Relações Internacionais Contemporâneas}

Na era informacional, a distribuição global do poder entre as nações não pode ser reduzida ao plano militar. Nye Jr. identifica três dimensões. No topo, o militar, que é nitidamente unipolar; no meio, uma economia em que vários pólos disputam o jogo e os Estados Unidos vêem limitada sua hegemonia diante de atores do porte da União Européia; e na base, relações de caráter transnacional: "o poder está disperso de forma caótica e não tem sentido utilizar termos tradicionais como 'unipolaridade', 'hegemonia', ou 'império americano"” (idem:137). Se o governo dos Estados Unidos concentrar sua estratégia em um jogo unilateral basicamente direcionado à dimensão militar, descuidará das duas dimensões em que o poder tende a diluir-se em uma gama ampla de atores. De uma perspectiva de amplitude global, essa postura pode redundar em perda crescente de influência. Para Nye Jr. (idem:146-147),

"A administração de Bush identificou corretamente a natureza dos novos desafios que enfrenta a nação e reorientou conseqüentemente a estratégia americana. Mas tanto a administração, como o Congresso e a população, dividiram-se entre diversas abordagens sobre a posta em prática da nova estratégia. $\mathrm{O}$ resultado tem sido uma mistura de êxitos e falhas. Estamos tendo mais sucesso no domínio do poder duro, em que investimos mais, treinamos mais, e temos uma idéia clara do que estamos fazendo. Temos acertado menos nas áreas do poder brando, em que a nossa diplomacia pública tem sido preocupantemente inadequada e a nossa negligência com os aliados e instituições têm criado um sentimento de ilegitimidade que desgasta nosso poder de atração".

A lógica do governo Bush foi bem sintetizada por Paul Wolfowitz (apud Gardels, 2002), secretário adjunto da Defesa no primeiro mandato, para quem os Estados Unidos estariam exercendo um papel de liderança no resguardo de interesses que envolvem a comunidade internacional, combatendo os países hostis que fomentam o terrorismo.

"Para nós, poder militar é muito mais um meio de defesa. A grande força dos EUA não é seu poderio militar, mas seu poder econômico. E mais potente 


\section{Luis Fernando Ayerbe}

ainda é nossa força política - aquilo que significamos. No mundo todo, mesmo em países cujos regimes nos odeiam, o povo admira o nosso sistema [...]. Claro que há diferença de interesses entre países, mas por causa do modo como definimos nossos interesses existe uma compatibilidade natural de interesses entre os EUA e os outros países" (idem:A25).

De acordo com Wolfowitz, não há unilateralismo, mas exercício legítimo do poder por parte de um Estado que utiliza sua força em nome do interesse geral. Para ele, o poderio militar norte-americano é "uma espécie de cerca protetora em torno da liberdade. Permite-nos fixar certas fronteiras; não admite que exércitos numerosos atravessem fronteiras" (ibidem).

\section{O (Novo) Imperialismo Norte-americano}

Ivo Daaler e James Lindsay (2003), ex-funcionários do Conselho de Segurança Nacional no governo Clinton e pesquisadores da Brookings Institution ${ }^{1}$, atribuem à política externa de George W. Bush um caráter revolucionário, não tanto por causa das metas, que não diferem no essencial das administrações anteriores, mas pelos meios adotados. Para os autores, duas crenças orientam a atuação internacional dos Estados Unidos:

"A primeira é que, em um mundo perigoso, a melhor - senão a única - maneira de proteger a segurança da América passa pela rejeição dos constrangimentos impostos por amigos, aliados e instituições internacionais. Maximizar a liberdade de ação da América é essencial pela posição única ocupada pelos Estados Unidos, que os transformou no alvo mais provável de todo país ou grupo hostil ao Ocidente. Os americanos não poderiam contar com outros para protegê-los; inevitavelmente, os países ignoram as ameaças que não os envolvem [...]. A segunda crença é que essa América desprovida de amarras deve usar sua força para mudar o status quo no mundo" (idem:13).

A partir do reconhecimento da incontestável superioridade militar, a contribuição "revolucionária" de Bush seria sua vontade e decisão de utilizá-la, enfrentando a resistência dos aliados e forçando definições 


\section{Os Estados Unidos e as Relações \\ Internacionais Contemporâneas}

em relação às prioridades da agenda internacional. No entanto, a aposta do presidente trouxe um resultado inesperado, com a rápida percepção dos limites que cercam o exercício do poder, enfrentando grandes dificuldades para conquistar e manter apoios para a segunda Guerra do Golfo.

A partir da invasão ao Iraque, tornam-se mais explícitas as controvérsias entre os que vêem na intervenção uma exacerbação contraproducente do poderio militar, os que vislumbram mais um sintoma de crise de hegemonia e os que defendem o papel dos Estados Unidos como nação indispensável, única disposta a adotar medidas extremas de acordo com a natureza dos desafios.

Entre os primeiros, a principal linha de questionamento passa pelas bases conceituais e argumentos políticos que fundamentam a preempção e a prevenção. Para Zbigniew Brzezinski (2004), assessor de Segurança Nacional na presidência de James Carter, as ações unilaterais do governo Bush pautam-se por uma visão do mundo em preto e branco que não admite matizes, cujo sustentáculo é uma doutrina de eficiência estratégica questionável.

"A preempção pode se justificar na base do supremo interesse nacional na presença de uma ameaça iminente, e assim, quase que por definição, é plausível que seja unilateral [...]. A prevenção, ao contrário, deve ser precedida, se possível, pela mobilização da pressão política (incluindo o apoio internacional) a fim de prevenir que ocorra o indesejável, e deve envolver o recurso da força somente quando outros remédios foram esgotados e a contenção não é mais uma alternativa digna de crédito" (idem:37).

Caso a superpotência cometa erros de avaliação na caracterização do tipo de ameaça a enfrentar, pode terminar iniciando uma guerra preventiva unilateral travestida de preempção. Embora reconheça a importância dos Estados Unidos como a única nação capaz de manter a ordem em um mundo em constante turbulência, Brzezinski aposta na sua capacidade para liderar um esforço multilateral em favor da criação de uma comunidade global de interesses compartilhados. No en- 
tanto, a nova doutrina, com sua decorrência imediata de invasão ao Iraque, tem levado a um isolamento crescente, configurando um curioso paradoxo: "A credibilidade militar global americana nunca foi tão alta, no entanto, sua credibilidade política global nunca foi tão baixa" (idem:214).

O viés militar da política externa dos Estados Unidos é enfatizado por Michael Mann (2004) na caracterização do que denomina "império incoerente". Apesar dos argumentos universais invocados pela administração Bush em favor da democracia, a liberdade e a prosperidade econômica, o autor chama a atenção para uma prática pautada basicamente na promoção dos interesses das elites dominantes, tanto daquelas mais próximas do Estado, como das que representam o poder dos chamados mercados, defensoras da disseminação global do neoliberalismo. A incoerência entre o discurso e a realidade estaria comprometendo cada vez mais a credibilidade internacional do país, sendo que a resposta das autoridades governamentais tende a pautar-se pela exacerbação do poderio militar, marca do novo imperialismo em construção.

Para Mann (idem:25-26), a superação do impasse ao qual o país está sendo levado pela administração Bush deverá vir fundamentalmente da mudança na correlação de forças na política nacional que se seguirá ao fracasso da atual política externa: "Com um pouco de sorte, a isso seguirá o abandono voluntário do projeto imperial por parte dos estadunidenses, o que, por sua vez, preservará em grande medida a hegemonia norte-americana".

Respondendo à pergunta sobre o que seria uma visão realista da atual configuração mundial do poder, em entrevista a Harry Kreisler (2003), do Instituto de Estudos Internacionais da Universidade da Califórnia, Kenneth Waltz resgata a atualidade das políticas de contenção e dissuasão: 


\section{Os Estados Unidos e as Relações \\ Internacionais Contemporâneas}

"Não importa o quão freqüentemente as pessoas da administração Bush digam que a 'contenção e a dissuasão não funcionam', funcionam da mesma forma que sempre em relação às finalidades para as quais sempre pensamos que estavam projetadas. Isto é, deter outros países de usar suas armas de forma que coloquem em perigo interesses manifestamente vitais dos Estados Unidos ou daqueles a quem dão apoio".

No caso da invasão ao Iraque, Waltz considera inadequada a aplicação dos argumentos em favor da preempção e da prevenção. O regime de Saddam Hussein não representava uma ameaça iminente de ataque aos seus vizinhos ou aos Estados Unidos, mantendo-se em uma posição defensiva. Por outro lado, sua capacidade potencial de transformar um país com um produto bruto de 15 bilhões de dólares, sob constante vigilância e controle por parte da Organização das Nações Unidas (ONU) e dos Estados Unidos, em uma futura potência nuclear estava fora de cogitação.

Para Waltz, o ex-dirigente do Iraque, assim como os demais líderes dos chamados Estados fora-da-lei, são sobreviventes de situações adversas que se estendem por longos períodos. "As pessoas insanas não se mantêm no poder contra um grande número de inimigos, seja internamente como externamente" (idem). Como sujeitos racionais que buscam permanecer no poder, são suscetíveis à contenção e à dissuasão.

O mesmo se aplica às redes terroristas como Al Qaeda, na eventualidade de chegarem a governar algum país, mesmo um que tenha armas nucleares, como o Paquistão. Para Waltz, as redes terroristas seriam socializadas pela lógica do poder estatal, amenizando seu radicalismo ideológico, principalmente o que justifica e estimula ataques suicidas. Nesse sentido, defende a contenção nuclear como estratégia de eficácia comprovada, independentemente da inimizade radical de certos regimes em relação aos Estados Unidos, citando como exemplo a trajetória da China de Mao Tse-Tung, que transitou da tur- 
bulência esquerdista dos anos da Revolução Cultural aos acordos com Nixon na década de 1970.

Em relação à situação de supremacia estadunidense que marca o período pós-Guerra Fria, Waltz descrê da capacidade de autocontrole da superpotência. "A característica-chave de um mundo unipolar é que não há nenhuma restrição e contrapeso a esse poder, então ele está livre para seguir sua fantasia, está livre para agir por seus caprichos" (idem).

Reafirmando a atualidade do realismo, Waltz (2002) vê a unipolaridade como um momento transitório por definição. O futuro surgimento de grandes potências a partir da projeção internacional da União Européia, Japão, China e Rússia acabará restaurando o equilíbrio de poder, tendência predominante das relações interestatais desde a segunda metade do século XVII.

Essa certeza é questionada por Ikenberry (2002a), que vê no ordenamento pós-Guerra Fria uma peculiaridade que considera persistente e estável: a cooperação entre as democracias do capitalismo avançado convivendo com a ausência de equilíbrio de poder. A permanência desta situação deve muito ao caráter liberal da hegemonia dos Estados Unidos, que Ikenberry considera inédito comparativamente às potências anteriormente predominantes no mundo ocidental. As marcas distintivas seriam a relutância em assumir explicitamente a primazia dos EUA, seu caráter penetrante, que gera transparência e se abre a Estados secundários, e sua alta institucionalidade, que permite o estabelecimento de mecanismos de interação pautados por regras consensuais.

As características apontadas outorgariam ao país a credibilidade necessária para consolidar uma liderança benigna e, conseqüentemente, aceitável para outros Estados, na promoção de uma ordem "construída em torno de interesses e valores comuns entre os países industriais avançados e ancorada no capitalismo e na democracia. Mas 


\section{Os Estados Unidos e as Relações \\ Internacionais Contemporâneas}

também uma ordem politicamente projetada, construída com base no poder americano, relações institucionais, e negociações políticas, particularmente com Europa e Japão" (idem:216).

A continuidade da tendência inaugurada pelo fim da bipolaridade depende da capacidade dos governos dos Estados Unidos de perceberem os ganhos estratégicos da autolimitação do uso do poder, apostando no fortalecimento das instituições, que Ikenberry considera um investimento hegemônico em uma ordem mais previsível e permanente "que proteja seus interesses no futuro" (idem:221).

Ikenberry situa suas posições em um campo distante do realismo e da hegemonia, abordagens estado-centristas que considera inadequadas para explicar a dinâmica dominante de uma ordem ocidental baseada em instituições, cuja salvaguarda não se assenta no equilíbrio, mas na liderança de uma potência essencialmente liberal, que poderá ter uma continuidade indeterminada, estreitamente vinculada à sabedoria com que exerça seu poder.

Em relação a esse último aspecto, o autor manifesta preocupações com as tendências unilaterais que marcam desde o início a administração Bush, acentuando-se após o 11 de Setembro, com a nova doutrina de segurança, que classifica como neo-imperial, ameaçadora das conquistas obtidas pelo país na construção da sua liderança. A persistência no unilateralismo seria altamente custosa, principalmente em quatro aspectos: 1) ao explicitar a decisão de agir preventivamente, poderia estimular respostas defensivas de outros países, que buscariam no desenvolvimento de programas de armas nucleares uma forma de dissuasão a eventuais ataques estadunidenses; 2) as intervenções militares trazem como conseqüência a implementação de ações de manutenção da paz e construção de nações que, dependendo do número e extensão das guerras movidas pelo país, gerarão uma carga econômica capaz de configurar o fenômeno da expansão excessiva; 3) a postura imperial dificulta as alianças, justamente em 
um contexto de luta contra o terrorismo que torna cada vez mais necessária a divisão de responsabilidades com sócios confiáveis; 4) ao superestimar seu próprio poder, o país pode cair na armadilha em que caíram no passado outros Estados imperiais, o autofechamento, levando os demais países a buscar alternativas que descartem uma dominação estadunidense.

Para Ikenberry (2002b:60), "mais do que inventar uma nova grande estratégia, os Estados Unidos deveriam revigorar as antigas, que se baseavam na idéia de que seus sócios em matéria de segurança não são meras ferramentas, mas elementos-chave de uma ordem política mundial a preservar dirigida pelos Estados Unidos".

A idéia de que o unilateralismo poderia representar o prenúncio de uma futura perda de hegemonia é compartilhada por diversos analistas, que apresentam um conjunto de fatos econômicos e políticos que fortaleceriam essa hipótese.

No âmbito da economia, a percepção de crise torna-se mais visível a partir da administração Bush, com a diminuição do ritmo de crescimento que caracterizou o período de Clinton, paralelamente ao aumento do desemprego e à forte expansão dos gastos com defesa, cujo orçamento teve, em 2003, um incremento de 37 bilhões de dólares em relação ao ano anterior, chegando a 355 bilhões e 400 milhões de dólares, ou quase $17 \%$ do orçamento nacional total do país, de 2 trilhões e 100 bilhões de dólares (Montoya, 2003). Para o ano fiscal de 2006, o secretário da Defesa solicitou 419,3 bilhões de dólares, o que representa, segundo os cálculos do próprio Departamento, uma elevação de 5\% em relação ao ano anterior e de $41 \%$ em relação a 2001 (Department of Defense, 2005). De acordo com Chalmers Johnson (2004:288), “93\% das alocações para assuntos internacionais estão indo para a área militar e apenas 7\% para o Departamento de Estado". 
Para além do aumento de gastos do governo Bush, alguns autores chamam a atenção para indicadores que expressam uma tendência de deterioração econômica que vêm de períodos anteriores: crescente déficit comercial, que passa de 100 bilhões de dólares em 1990 para 450 bilhões em 2000, necessitando de entradas financeiras de 1 bilhão por dia para cobri-lo; concentração da renda, que para os 5\% mais ricos passa de $15,5 \%$ em 1980 para $21,9 \%$ em 2000 e para os $80 \%$ menos ricos cai de 56,9\% para 50,6\% (Todd, 2003); dependência energética, dado que o país conta com apenas $5 \%$ da população mundial, $2 \%$ das reservas globais de petróleo e $11 \%$ da produção petroleira mundial, mas consome quase $26 \%$ do total extraído no mundo, sendo que, para os próximos vinte anos, calcula-se um incremento no seu consumo de 6 milhões de barris diários (Rifkin, 2002).

A dimensão petroleira é um dos aspectos destacados por David Harvey (2004) na sua caracterização das motivações do militarismo de Bush no Oriente Médio. Situando-se no campo do marxismo, sua abordagem toma como referência a interação entre as estratégias do Estado e do capital, como atores centrais da variedade capitalista do imperialismo. Dessa perspectiva, a ação no Iraque articula interesses que vão além do conjuntural em termos de garantir a presença de um governo confiável em um país que detém as segundas maiores reservas de petróleo, favorecendo um aumento da produção capaz de diminuir o mais rapidamente possível os preços do barril. Considerando que grandes competidores internacionais dos Estados Unidos nos campos da produção e das finanças, como Europa, Japão e o Leste da Ásia, incluindo a China, são fortemente dependentes do petróleo da região do Golfo Pérsico, Harvey (idem:30) formula duas questões importantes sobre as motivações do intervencionismo de Bush:

"Que melhor forma de os Estados Unidos evitarem essa competição e garantirem sua posição hegemônica do que controlar o preço, as condições e a distribuição do recurso econômico decisivo de que dependem esses competidores? E que modo melhor de fazê-lo do que usar a linha de força em que os Estados Unidos ainda permanecem todo-poderosos - o poder militar?". 
Essa postura, embora expresse uma racionalidade estratégica, é reveladora da ausência de outras opções capazes de reverter um quadro de crescente deterioração da competitividade internacional da economia dos Estados Unidos. Neste aspecto, Harvey partilha das posições de Arrighi e Silver (2001) de que está em andamento um processo de transição hegemônica, em que o declínio busca ser compensado com políticas explícitas de dominação.

No campo dos argumentos políticos, alguns autores europeus começam a questionar a relevância mundial que os Estados Unidos se atribuem. Para Emmanuel Todd (2003), os fatores econômicos acima apontados geram uma crescente necessidade de inflacionar ameaças, alimentando o ativismo internacional do país. Isto levaria seu governo a assumir um "militarismo teatral" composto por três características principais:

“-Nunca resolver definitivamente um problema, para justificar a ação militar indefinida da 'única superpotência' em escala planetária.

- Fixar-se em micropotências - Iraque, Irã, Coréia do Norte, Cuba, etc. A única maneira de continuar politicamente no centro do mundo e 'enfrentar' atores menores.

- Desenvolver novas armas que supostamente poriam os Estados Unidos 'muito à frente', numa corrida armamentista que não pode mais cessar"' (idem:32).

Todd (idem:98) aposta na insustentabilidade do império americano, cuja desaparição ocorreria antes de 2050, por duas razões básicas:

"Seu poder de coerção militar e econômica é insuficiente para manter o nível atual de exploração do planeta; seu universalismo ideológico está em declínio e não lhe permite mais tratar os homens e os povos de maneira igualitária, para garantir-lhes a paz e a prosperidade tanto quanto para explorá-los".

Na mesma direção de Todd, Alain Joxe (2003) critica a fragilidade das premissas em que se apóia o atual poderio americano, que caracteriza como império do caos, ao assumir uma ação de combate aos 


\section{Os Estados Unidos e as Relações Internacionais Contemporâneas}

sintomas e não às causas dos conflitos que se disseminam pelo mundo, construindo um "sistema que apenas se consagra a regular a desordem por meio de normas financeiras e expedições militares, sem um projeto de permanência no terreno conquistado" (idem:21). Caso continue predominando essa postura na política externa dos Estados Unidos, o autor vê como tendência a emergência de um regime antidemocrático mundial, diante do qual propõe a recuperação da tradição republicana européia, que considera menos maniqueísta na abordagem dos conflitos, pautando suas relações exteriores pelo respeito à pluralidade, pela tolerância, a não-intervenção e a busca de uma maior eqüidade econômica e social. Nessa tradição, a tirania

“[...] não é considerada como não humana senão como um modo de governo antidemocrático; a luta de classes não é um crime senão um estado normal das sociedades desenvolvidas que deve pacificar-se na democracia, mas não 'desaparecer'. A redistribuição da renda mediante um procedimento voluntário de partilha equiitativa é o abc da ciência política desde Aristóteles, e não o pensamento delirante de um subversivo louco. A visão européia em relação ao Outro, concebida como oposição política, é portanto essencialmente diferente da dos estadunidenses, que a constroem como exclusão" (idem:239-240).

Para Ulrich Beck (2004), a União Européia exemplifica as possibilidades de construção de um sistema estatal transnacional e cosmopolita, resposta necessária a uma dinâmica global que já não pode ser interpretada por meio de leituras nacionais. O conceito adequado é o de "metajogo" da política mundial, cenário no qual interatuam seus três grandes protagonistas, os Estados, o capital e a sociedade civil global, configurando um equilíbrio de poderes em que nenhum ator tem condições de impor seus interesses.

“Todos necessitam coligar-se para tornar realidade seus objetivos respectivos, o que põe em funcionamento uma dinâmica de entrelaçamento, [...] um regime de inimigos sem inimigos, ou seja, um regime que integra os oponentes mediante a reprodução inclusiva, com o que está perfeitamente em situação de gerar e renovar o dissenso-consenso que assegura seu próprio espaço de poder" (idem:377; 379). 
Em termos estratégicos, o desenvolvimento desse processo de transnacionalização da economia e da política conduziria à conformação de um Estado cosmopolita, capaz de reconhecer e defender a igualdade e a diversidade nas dimensões étnicas e nacionais. Para Beck, a política externa dos Estados Unidos pós-11de setembro caminha em direção contrária a essa tendência, na medida em que atribui ao Estado nacional um papel vigilante e interventor com autonomia para sacrificar a legalidade dentro e fora do país em nome do combate ao terrorismo, ao mesmo tempo em que promove de forma sistemática a universalização dos valores do seu modo de vida, edificando um "despotismo cosmopolita".

Entre os europeus, existem vozes discordantes sobre o questionamento do unilateralismo de George W. Bush e os anúncios de uma Europa "essencialmente diferente". Para Jean-François Revel (2003), há uma obsessão antiamericana que, além do envolvimento dos atores mais óbvios à esquerda, traz para o primeiro plano governos aliados dos Estados Unidos, cujas manifestações contra a sua política externa tendem muitas vezes a superar as dos partidários e simpatizantes do comunismo dos anos da Guerra Fria.

Sem desconhecer os méritos nacionais da atual preponderância norte-americana, Revel (idem:46) chama a atenção para os fatores que se originam do vazio de poder provocado por situações criadas externamente: "a falência do comunismo, o naufrágio da África, as divisões européias e os atrasos democráticos da América Latina e da Ásia”. Por outro lado, questiona a atribuição da principal responsabilidade pelos conflitos e calamidades econômicas e sociais que assolam o mundo à vocação imperial da superpotência. Afinal, muitos desses problemas carregam o peso de um passado recente em que a Europa foi um protagonista essencial.

“À situação criada pelas tentativas européias de suicídio, constituídas pelas duas guerras mundiais e a propensão dos europeus para engendrar os regimes totalitários, estes também intrinsecamente suicidas, veio juntar-se, a 


\section{Os Estados Unidos e as Relações \\ Internacionais Contemporâneas}

partir de 1990, a obrigação de absorver o campo de ruínas deixado pelo comunismo, após seu colapso" (idem:47).

A decadência européia tem seqüelas nos conflitos presentes em regiões que eram parte dos seus impérios coloniais, cuja desagregação deixou marcas permanentes no chamado "terceiro mundo". O reconhecimento do peso das suas ações e omissões como um dos fatores responsáveis pela preponderância dos Estados Unidos e a adoção de uma posição que, além de cooperativa, exerça um papel vigilante contra os eventuais abusos da superpotência, são as principais recomendações de Revel para a recuperação de um maior protagonismo europeu. A continuidade do antiamericanismo obsessivo só fortalecerá o unilateralismo, na medida em que o governo dos Estados Unidos, contando de antemão com o posicionamento crítico dos aliados ocidentais, tenderá a agir cada vez mais por conta própria, sendo que, ao menos por um bom tempo, conta com os recursos de poder necessários para isso.

No âmbito dos conservadores norte-americanos, as posições defendidas por Revel têm uma presença muito mais expressiva. Entre os nomes de destaque está Robert Kagan (2003), um dos fundadores, junto com William Kristol, do Project for the New American Century ${ }^{2}$. Para ele, a existência de visões divergentes entre os Estados Unidos e a Europa é incontestável, especialmente "na importantíssima questão do poder, da eficácia do poder, da moralidade do poder, da vontade de poder" (idem:7).

“A Europa está afastando-se do poder, ou, em outras palavras, está caminhando para além do poder, rumo a um mundo isolado repleto de leis, normas, negociações e cooperação internacional. Está entrando num paraíso pós-histórico de paz e relativa prosperidade, a concretização da 'paz perpétua de Immanuel Kant. Os Estados Unidos, entretanto, continuam chafurdando na história, exercendo o poder num mundo hobbesiano anárquico, onde as leis e as diretrizes internacionais não são dignas de confiança, a verdadeira segurança, a defesa e a promoção da ordem liberal ainda dependem da posse e do uso do poderio militar" (ibidem). 


\section{Luis Fernando Ayerbe}

A despeito do reconhecimento da diversidade de percepções e posições, os contrastes não expressariam a oposição entre uma Europa essencialmente pacifista e democrática e uns Estados Unidos com vocação natural ao exercício realista do poder, mas capacidades diferenciadas, embora ao mesmo tempo complementares, de uso da força. Para Kagan, mais que uma escolha baseada em princípios, a atual postura da Europa não difere daquela adotada pelos Estados Unidos no século XIX, então militarmente pouco expressivos, cujo cálculo estratégico de acúmulo de poder recomendava uma política de afastamento das disputas hegemônicas entre as potências européias, cuja visão do mundo refletia o momento de auge do seu poder econômico, militar e colonial. Nos dias atuais, as posições invertem-se, e Estados Unidos e Europa assumem posições equivalentes ao seu peso nas relações internacionais. No entanto, há um paradoxo na posição européia, cuja

“[...] passagem à pós-história dependeu do fato de os Estados Unidos não fazerem tal passagem. Por não ter disposição nem capacidade de proteger seu próprio paraíso e impedir que seja invadido, tanto espiritual quanto fisicamente, por um mundo que ainda não adotou a lei da 'consciência moral', a Europa tornou-se dependente da disposição americana de usar seu poderio militar para conter e derrotar aqueles que, ao redor do mundo, ainda são partidários da política do poder" (idem:75).

As expedições armadas que atacam os sintomas e não as causas das crises, que Joxe (2003) associa a um Império do Caos, são funcionais à indisposição da Europa para assumir um maior envolvimento, especialmente quando se desencadeiam em seu próprio território, como aconteceu com os conflitos nos Bálcãs nos anos 1990.

Para Kagan (2003), tanto a posição adotada pela Europa quanto a dos Estados Unidos não vão sofrer alterações substanciais. A não ser que aconteça uma catástrofe militar ou econômica cujas proporções abalem a continuidade do poder estadunidense, "é razoável presumir 


\section{Os Estados Unidos e as Relações Internacionais Contemporâneas}

que acabamos de ingressar numa longa era de hegemonia americana" (idem:90).

Alguns indicadores tendem a reforçar essa avaliação, especialmente os que se referem aos custos de manutenção da atual política para a economia nacional, que não seriam insuperáveis. Em relação aos déficits externos, o financiamento do consumo americano seria funcional à estabilidade da economia mundial, garantindo superávits comerciais para diversos países e regiões, como mostram os dados do Quadro 1.

\section{Quadro 1}

Balança Comercial dos Estados Unidos com Países e Regiões Selecionados -2003 e 2004

\begin{tabular}{|l|cc|}
\hline \multicolumn{1}{|c|}{ País/Região } & \multicolumn{2}{c|}{ Déficit Comercial dos Estados Unidos } \\
& $\mathbf{2 0 0 3}$ & $\mathbf{2 0 0 4}$ \\
\hline China & $-124,068.2$ & $-161,938.0$ \\
Japão & $-66,032.4$ & $-75,562.1$ \\
Europa Ocidental & $-100,320.3$ & $-113,378.8$ \\
México & $-40,648.2$ & $-45,066.5$ \\
América do Sul e Central & $-26,882.8$ & $-37,183.3$ \\
Coréia do Sul & $-13,156.8$ & $-19,755.5$ \\
Israel & $-5,876.5$ & $-5,382.4$ \\
Rússia & $-6,170.7$ & $-8,930.3$ \\
\hline
\end{tabular}

Fonte: Elaborado com base no U.S. Census Bureau, Department of Commerce: Country Data (http://www.census.gov/foreign-trade).

No âmbito dos gastos dos EUA com despesas militares como porcentagem do Produto Nacional Bruto (PNB), conforme assinala o próprio Todd (2003), houve uma queda considerável, passando de $7 \%$ no fim dos anos 1980 para 5,2\% em 1995 e $3 \%$ em 1999. No auge da hegemonia inglesa, entre 1815 e a década de 1870 , os gastos estadunidenses com as forças armadas variava entre $2 \%$ e $3 \%$ do PNB (Kennedy, 1989). 
Niall Ferguson (2004), um defensor explícito da necessidade do império estadunidense como fator de estabilidade e progresso mundial, relativiza o impacto dos gastos militares na economia do país. Há um problema de déficits crônicos das finanças nacionais que não se originam dos compromissos externos assumidos pelas forças armadas. Para sustentar seu argumento, compara o volume dos gastos militares dos Estados Unidos, que excedem o conjunto dos orçamentos de defesa da União Européia, China e Rússia, com a parcela que consome do PNB, correspondente a uma média de 3,5\% na primeira metade da década de 2000, bem menor do que os $10 \%$ dos anos 1950. Desta forma, conclui: "Assim como o império liberal britânico um século atrás, o nascente império liberal americano é surpreendentemente barato para funcionar" (idem:262).

Para Ferguson, o mundo necessita mais do que nunca de um império benigno, liderado pelos Estados Unidos, mas que busque trazer para seu lado a União Européia, cujo caráter liberal não apenas

"[...] subscreve a troca internacional livre dos produtos, do trabalho e do capital, mas também cria e sustenta as condições sem as quais os mercados não podem funcionar - a paz e a ordem, o império da lei, uma administração não corrupta, políticas fiscais e monetárias estáveis, assim como fornece bens públicos, tais como infra-estrutura para o transporte, hospitais e escolas, que não existiriam de outra maneira" (idem:2).

Embora Ferguson considere o império uma condição inerente à história dos Estados Unidos, nem sempre se assumiu enquanto tal, o que estaria mudando a partir da administração Bush e do 11 de Setembro.

\section{O Desafio Conservador}

Sistematizando as posições dos autores que vinculam o unilateralismo com a perda de capacidade dos Estados Unidos para gerar consensos na administração do sistema internacional, destacam-se três argumentos: 1) a exacerbação do poder duro, apesar de eventuais ganhos conjunturais, tende a comprometer a posição de supremacia a 


\section{Os Estados Unidos e as Relações Internacionais Contemporâneas}

médio e longo prazo; 2) a manutenção do status de única superpotência global torna-se cada vez mais dependente de respaldo financeiro externo, em um contexto de crise da economia e fortalecimento crescente do setor privado transnacional; 3) o aprofundamento das desigualdades promovido pelo modelo econômico vigente, incapaz de responder às demandas da maioria dos excluídos do sistema, está cristalizando um impasse social.

No contexto atual, o impasse social assume formas diversas: fundamentalismo antiocidental, com desdobramentos na perpetração de atentados terroristas como os de 1998 nas embaixadas de Quênia e Tanzânia, ganhando maior fôlego a partir do 11 de Setembro; as crises financeiras inauguradas pela desvalorização do peso mexicano em dezembro de 1994, atingindo posteriormente a Coréia do Sul, a Rússia, o Brasil e a Argentina; movimentos sociais contra a agenda de liberalização dos mercados, que assumem maior visibilidade a partir das manifestações de rua paralelas à reunião da OMC em Seattle, em novembro de 1999; fortalecimento de partidos críticos da ordem nos eleitorados do "terceiro mundo", com possibilidades concretas de alcançar o poder governamental, tendo-se Venezuela, Brasil e Uruguai como exemplos mais emblemáticos na América Latina.

Diante desse cenário, a percepção do caráter irremediável e irreversível da polarização entre países e setores sociais - pelo menos a curto e médio prazo - conduz o governo dos Estados Unidos a optar pela explicitação dos limites que demarcam a segurança do sistema, deflagrando uma campanha de amplo espectro destinada a diminuir níveis de incerteza, combatendo os "novos bárbaros" que se disseminam pelos territórios do império.

A radicalização de posições por parte do governo Bush não está associada ao abandono do consenso hegemônico, decorrente da aceleração de uma crise de caráter estrutural que impõe a dominação aberta como única alternativa. O que se verifica é uma sinalização em favor 


\section{Luis Fernando Ayerbe}

do endurecimento, como ação preventiva contra os fatores de instabilidade associados a uma conjuntura de transição entre o mundo bipolar e a nova ordem em configuração.

O antecedente mais próximo dessa postura na política externa é a administração de Ronald Reagan, que enfrentou um contexto mais delicado, envolvendo diversas frentes: no aspecto econômico, o segundo choque do petróleo, a recessão mundial e a perda de posições do país em relação ao Japão e à então Alemanha Ocidental; no âmbito político, as seqüelas da derrota no Vietnã e do escândalo Watergate, paralelamente à expansão da esfera de influência da União Soviética e às revoluções no Irã e na Nicarágua.

O unilateralismo daquele momento, com a diplomacia do dólar forte e o combate ao "império do mal", foi a opção de uma equipe oriunda de círculos neoconservadores ${ }^{3}$, cuja influência se estende às administrações de Bush pai e filho. A convicção desses modernos adeptos do big stick de que a derrota soviética e a retomada da hegemonia dos Estados Unidos decorrem fundamentalmente do sucesso das políticas adotadas nos anos 1980 fortalece o favoritismo em prol da deflagração de uma nova cruzada.

Diferentemente daquele contexto, não se visualizam no horizonte novos inimigos do sistema. As organizações que defendem programas anticapitalistas, além de pouco expressivas, não contam com o respaldo de potências nucleares com ambições internacionais hegemônicas. Nos países governados por partidos originários da esquerda, predomina uma postura internacional pautada pela negociação das diferenças e respeito da legalidade. Na América Latina, isto inclui regimes políticos de partido único, como Cuba, e regimes de democracia representativa, como o Brasil. Os movimentos sociais antiglobalização questionam, basicamente, seus desajustes, especialmente a exclusão, diferentemente da esquerda comunista, que colocava o acento da crítica na propriedade privada dos meios de produ- 


\section{Os Estados Unidos e as Relações}

ção e na extração de excedente no processo de trabalho, buscando atingir os fundamentos do capitalismo.

Expandir o acesso e a inclusão torna-se um dos desafios estratégicos da ordem proclamada pelos Estados Unidos. No entanto, enquanto não se verificam ganhos significativos nesse campo, a opção pelo endurecimento busca tornar mais explícitos os limites estruturais da mudança possível, colocando a economia de mercado e a democracia liberal como fundamentos inegociáveis de um modo de vida a preservar. Tendo essa perspectiva estratégica como referência central, o governo Bush entra em campo na disputa pelo apoio político dos "ganhadores" da globalização, deixando claro que, se o momento é de guerra, a defesa das hierarquias conquistadas antepõe-se a perdas conjunturais e localizadas de liberdade e bem-estar material, exigindo o fechamento de fileiras contra o crescente ativismo dos "perdedores", que estaria contaminado por uma irracionalidade com fortes componentes de ressentimento e destruição. A partir do momento em que se configure um desenlace favorável no combate aos novos inimigos, será possível restabelecer a normalidade. Enquanto isso, caberá aos "falcões" cuidar da governabilidade sistêmica, assumindo os custos políticos do Estado de exceção.

Da minha perspectiva, a atuação internacional dos Estados Unidos tem uma dimensão essencialmente estrutural. As diferenças entre o "unilateralismo" republicano e o "multilateralismo" democrata, os defensores dos poderes brando ou duro, as abordagens cosmopolitas, imperiais ou nacionais, realistas ou liberais, referem-se mais aos meios do que aos fins da política externa. Neste contexto, não se vislumbram ameaças à continuidade da ordem mundial cuja defesa anima o espírito da Doutrina Bush.

Ao longo de sua história, e de acordo com os desafios de cada época e de cada país, o capitalismo conviveu com regimes monárquicos, de 


\section{Luis Fernando Ayerbe}

democracia representativa, totalitarismos nazifascistas, ditaduras militares, nacionalismos populistas. Por que desta vez seria diferente?

Da mesma forma ocorrida na transição do século XIX para o XX, o exercício da hegemonia do imperialismo atual busca respaldo em parcela significativa das audiências nacionais e dos governos dos países do capitalismo avançado e atrasado, construindo um poder que se pretende incontestável nas dimensões econômica, militar, política e cultural.

\section{Notas}

1. A Brookings Institution é considerada o mais antigo Think Tank dos Estados Unidos. Fundada em 1916, atua nas áreas de educação, economia, política externa e governança. Em termos políticos, assume uma opção explícita pelas posições moderadas, acima de definições partidárias, embora seja considerada tradicionalmente próxima ao Partido Democrata. William Cohen, secretário da Defesa, Lawrence Summer, secretário do Tesouro, e Joan Edelman Spero, subsecretária do Departamento de Estado para Economia, Negócios e Agricultura do governo Clinton, pertenceram à instituição.

2. O Project for the New American Century, criado em 1997, tem entre os membros fundadores intelectuais conservadores, como Norman Podhoretz e Francis Fukuyama, e figuras que têm forte protagonismo na administração de George W. Bush, como Elliott Abrams, Jeb Bush, Dick Cheney, Paula Dobriansky, Zalmay Khalilzad, Lewis Libby, Donald Rumsfeld e Paul Wolfowitz.

3. O neoconservadorismo tem uma forte presença intelectual nos Estados Unidos, que envolve principalmente a participação em Think Tanks como o American Enterprise Institute e The Project for the New American Century, e a veiculação de idéias por meio de publicações periódicas, em que se destacam Commentary, The Public Interest e The Weeckly Standard. Em termos de influência política, adquiriu grande visibilidade durante o governo Reagan, que se ampliou na administração de George W. Bush, especialmente após o 11 de Setembro de 2001, quando os neoconservadores assumiram a liderança na formulação das novas diretrizes da política externa. 
ARRIGHI, Giovanni e SILVER, Beverly. (2001), Caos e Governabilidade no Moderno Sistema Mundial. Rio de Janeiro, Contraponto/Editora UFRJ.

AYERBE, Luis Fernando. (2003), O Ocidente e o Resto. A América Latina e o Caribe na Cultura do Império. Buenos Aires, Clacso-Asdi. Disponível na internet em <http://www.clacso.org/wwwclacso/espanol/html/libros/ayerbe/ayerbe. html $>$.

BECK, Ulrich. (2004), Poder y Contrapoder en la Era Global. Barcelona, Paidos.

BRZEZINSKI, Zbigniew. (2004), The Choice. New York, Basic Books.

CECEÑA, Ana Esther. (2002), “La batalla de Afganistán”, in A. E. Ceceña e E. Sader (coords.), La Guerra Infinita. Hegemonía y Terror Mundial. Buenos Aires, Clacso-Asdi.

DAALER, Ivo e LINDSAY, James. (2003), America Unbound. Washington D.C., Brooking Institution Press.

DEPARTMENT OF DEFENSE. (2005), "DoD News: Fiscal 2006 Department of Defense Budget is Released". Disponível na internet em <http://www. defenselink.mil/releases/2005/nr20050207-2066.html>.

FERGUSON, Niall. (2004), Colossus. The Price of America's Empire. New York, The Penguin Press.

GARDELS, Nathan. (2002), "EUA 'O Poderio Americano, uma Cerca Protetora da Liberdade'”, $O$ Estado de São Paulo, 5 de maio.

HARDT, Michael e NEGRI, Antonio. (2001), Império. Rio de Janeiro, Record.

HARVEY, David. (2004), O Novo Imperialismo. São Paulo, Edições Loyola.

HUNTINGTON, Samuel. (1993), “The Clash on Civilizations?”. Foreign Affairs, vol. $72, \mathrm{n}^{\circ} 5$.

. (1997), O Choque de Civilizações e a Recomposição da Ordem Mundial. São Paulo, Objetiva. 


\section{Luis Fernando Ayerbe}

. (2000), “A Superpotência Solitária”. Política Externa, vol. 8, nº 4.

. (2004), Who Are We? The Challenges to America's National Identity. New York, Simon\&Schuster.

IKENBERRY, John. (2002a), "Democracy, Institutions and American Restraint", in J. Ikenberry (ed.), America Unrivaled. The Future of Balance of Power. Ithaca, Cornell University Press.

_. (2002b), “America’s Imperial Ambition”. Foreign Affairs, vol. 81, no 5.

JOHNSON, Chalmers. (2004), The Sorrows of Empire. New York, Metropolitan Books.

JOXE, Alain. (2003), El Imperio del Caos. México, Fondo de Cultura Económica.

KAGAN, Robert. (2003), Do Paraíso e do Poder. Rio de Janeiro, Rocco.

KENNEDY, Paul. (1989), Ascensão e Queda das Grandes Potências. Rio de Janeiro, Campus.

KREISLER, Harry. (2003), “Conversations with History”. Institute of International Studies, University of California, Berkeley. Disponível na internet em $<$ http://globetrotter.berkeley.edu/people3/Waltz/waltz-con1.html>.

MANN, Michael. (2004), El Imperio Incoherente. Barcelona, Paidos.

MONTOYA, Roberto. (2003), El Imperio Global. Buenos Aires, El Ateneo.

NSC - National Security Council. (2002), “The National Security Strategy of the United States of America”. Washington, D.C., 17 de setembro. Disponível na internet em <http://www.whitehouse.gov/nsc/nss.html $>$.

NYE JR., Joseph. (2004), Soft Power: The Means to Success in World Politics. New York, Public Affairs.

POWELL, Colin. (2001), "Interview by BBC, Secretary Colin L. Powell”. Washington, D.C., 21 de setembro. Disponível na internet em <http://www.state.gov/secretary/former/powell/remarks/2001/5004.htm>.

REVEL, Jean-François. (2003), A Obsessão Antiamericana. Causas e Inconseqüências. Rio de Janeiro, UniverCidade.

RIFKIN, Jeremy. (2002), La Economía del Hidrógeno. Buenos Aires, Paidos. 


\section{Os Estados Unidos e as Relações \\ Internacionais Contemporâneas}

TODD, Emmanuel. (2003), Depois do Império. São Paulo, Editora Record.

WALTZ, Kenneth. (2002), "Structural Realism after the Cold War”, in J. Ikenberry (ed.), America Unrivaled. The Future of Balance of Power. Ithaca, Cornell University Press.

\section{Resumo}

\section{Os Estados Unidos e as Relações Internacionais Contemporâneas}

O artigo analisa a posição dos Estados Unidos nas relações internacionais pós-Guerra Fria, tomando como referência as controvérsias sobre os alcances e limites da sua postura hegemônica, que adquirem maior impulso a partir da formulação da chamada "doutrina Bush", sistematizada no documento "A Estratégia de Segurança Nacional dos EUA".

No tratamento da temática proposta, enfatizam-se os seguintes aspectos: estabelecimento de um paralelo entre a transição dos séculos XIX-XX e XX-XXI, situando as características do imperialismo de cada época; uma análise da atual política externa dos Estados Unidos, enfocando o debate entre unilateralismo e multilateralismo, com destaque para as reações geradas pela intervenção no Iraque; uma discussão crítica das abordagens que visualizam na agenda de segurança da administração Bush um indicador de perda de hegemonia, que imporia a substituição da busca do consenso pela dominação aberta.

Palavras-chave: Bush - Unilateralismo-Multilateralismo-Hegemonia 


\section{Abstract}

\section{The United States in the Present International Relations}

This article analyzes the position of the United States in the post-Cold War world, considering as a reference the controversies on the extension and limits of its hegemonic posture, which acquires greater relevance after the formulation of the "Bush Doctrine", systematized in the document "The National Security Strategy of the United States of America".

Our approach will lay emphasis on the following aspects: establishment of a parallel between the transition of the XIX-XX and XX-XXI centuries, from studies that point out the characteristics of imperialism at different times; an analysis of the current foreign policy of the United States, focusing on the debate between unilateralism and multilateralism, emphasizing the reactions caused by the intervention in Iraq; a critical argument of the approaches that visualize in the security agenda of the Bush administration an indicator of a loss of hegemony, which would impose open domination over the search of consensus.

Key words: Bush Doctrine - Unilateralism - Multilateralism Hegemony 